\title{
INFLUÊNCIA DA REMOÇÃO DE COTILÉDONES NO DESENVOLVIMENTO DE RAMIFICAÇÕES NAS AXILAS COTILEDONARES DE PLÂNTULAS DE LEGUMINOSAS
}

\author{
Odaci Fernandes de Oliveira ${ }^{1}$ \\ Patrícia Ligia Dantas de Morais ${ }^{2}$
}

Recebido em 13/11/1998. Aceito em 29/07/1999

\begin{abstract}
RESUMO - (Influência da remoção de cotilédones no desenvolvimento de ramificações nas axilas cotiledonares de plântulas de leguminosas). Experimentos inteiramente casualizados foram conduzidos em condições de viveiro com o objetivo de verificar a importância da permanência de cotilédones no desenvolvimento de ramificações nas axilas cotiledonares de plântulas de Phaseolus vulgaris L., Vigna unguiculata (L.) Walp., Leucaena leucocephala (Lam.) De Wit, Prosopis juliflora (Sw.), Tamarindus indica L. e Delonix regia L. Os tratamentos foram: remoção de ambos os cotilédones nos primeiro, segundo e terceiro dias da emergência, remoção de um só cotilédone no primeiro dia da emergência e não remoção de cotilédones. A recuperação do desenvolvimento em plântulas de $P$. vulgaris, avaliada através da ocorrência de ramificações, independe do número de cotilédones removidos no período de um a três dias da emergência, mas é menos eficiente que em $V$. unguiculata. A remoção de ambos os cotilédones em plântulas de $V$. unguiculata, no dia da emergência, afetou a recuperação do desenvolvimento dessas plântulas em comparação com os outros tratamentos. Em plântulas de L. leucocephala, $P$. juliflora, $T$. indica e D. regia, a remoção de ambos os cotilédones, no período de um a três dias da emergência, sugere o aumento de mortalidade nessas plântulas. A remoção de um único cotilédone não afetou significativamente o percentual de sobrevivência das plântulas nem limitou o surgimento de brotações à axila cotiledonar correspondente ao cotilédone removido.
\end{abstract}

Palavras-chave - remoção de cotilédones, função dos cotilédones, desenvolvimento de plântulas, leguminosas

\begin{abstract}
Effect of cotyledon removal on cotyledonal axillary shooting in seedlings of leguminosae). Completely randomized experiments under greenhouse conditions were carried to study the role of cotyledons on the cotyledonal axillary shooting of Phaseolus vulgaris L., Vigna unguiculata (L.) Walp., Leucaena leucocephala (Lam.) De Wit, Prosopis juliflora (Sw.), Tamarindus indica L. and Delonix regia L. The seedlings underwent the following treatments: removal of both cotyledons on the first to the third day after emergence, removal of only one cotyledon on the first day of emergence, and no cotyledon removal. Growth recovery in $P$. vulgaris seedlings, as evaluated through shooting occurrence, is independent of the number of cotyledons removed on the first to the third day after emergence, but it was mostly less effective than that in $V$. unguiculata. Growth recovery in $V$. unguiculata seedlings was less effective when both cotyledons were removed on the first day of emergence as compared to the other treatments. In $L$. leucocephala, $P$. juliflora, $T$. indica, and D. regia seedlings, the removal of both cotyledons, on the first to the third day after emergence, suggests an increase in the mortality of seedlings. The removal of only one cotyledon did not significantly affect the percentage of seedling survival nor limit shooting to the corresponding axil of the removed cotyledon.
\end{abstract}

Key words - cotyledon removal, cotyledon function, seedling growth, leguminosae 


\section{Introdução}

Estudos in vivo e in vitro sobre o papel dos cotilédones em várias espécies têm demonstrado que esses órgãos exercem grande influência no desenvolvimento das plantas. Verificou-se, por exemplo, decréscimo no crescimento de plântulas de Phaseolus vulgaris quando a remoção dos cotilédones ocorre nos primeiros dez dias de vida da planta (Hotta, citado por Chin et al. 1977); a remoção de cotilédones aos 14 dias do plantio, além de causar decréscimo na taxa de crescimento das plantas de Vicia faba, causou também diminuição no peso dos nódulos de Rhizobium em suas raízes, ao passo que a remoção dos cotilédones realizada aos 18 dias do plantio não afetou o desenvolvimento das plantas, mas aumentou o número e o peso dos nódulos (Silsbury \& Silsbury 1992); tanto o crescimento como a sobrevivência das plântulas de Quercus laurina e $Q$. rugosa foram afetados drasticamente pela excisão dos cotilédones realizada um mês após a germinação (Bonfil 1998); na região subapical dos hipocótilos de plântulas de Helianthus annuus, cujos cotilédones foram removidos, houve paralisação do alongamento celular em decorrência da diminuição da pressão de turgor (Kutschera \& Kohler 1994); a redução do acúmulo de matéria, em função da remoção de cotilédones, é acompanhada pela redução no conteúdo de carboidratos no eixo das plântulas de Dalbergia miscolobium (Sassaki \& Felippe 1992); durante o desenvolvimento inicial de Qualea grandiflora, os cotilédones contribuem para o crescimento do eixo embrionário através da translocação de carboidratos, mas não de nitrogênio, tendo o não fornecimento de nitrogênio sido sugerido pelo fato de se ter encontrado o mesmo teor em proteína solúvel nos cotilédones, durante nove semanas de crescimento do eixo caulinar (Paulilo \& Felippe 1994); houve alterações nas concentrações de lipídios nos cotilédones e no eixo da plântula de Citrullus lanatus, ao longo de oito dias após a germinação (Meletiou-Christou et al. 1990); em Glycine max há transferência de aproximadamente $0,45 \%$ de enxofre $(\mathrm{p} / \mathrm{v})$ dos cotilédones para os nomófilos durante o desenvolvimento inicial das plântulas (Sunarpi \& Anderson 1995); em Citrus paradisi, plântulas obtidas in vitro, a partir de embriões cujos cotilédones foram removidos, sofreram diminuição no alongamento de seus eixos (Holland et al. 1995); a ausência completa de cotilédones nos explantes de embriões de Cucumis sativus resultou na não produção de brotações adventícias na base dos hipocótilos (Gambley \& Dood 1991); há um mecanismo envolvendo transporte, armazenamento e recuperação da mensagem de quebra de assimetria, que controla a taxa de crescimento das gemas cotiledonares em Bidens pilosa (Desbiez et al. 1991).

Considerando os dados da literatura e que em Phaseolus vulgaris, Vigna unguiculata, Leucaena leucocephala, Prosopis juliflora, Tamarindus indica e Delonix regia há algumas diferenças na forma, na espessura, no tamanho $\mathrm{e}$ na coloração dos cotilédones após a emergência, e ainda que essas espécies são representantes das três subfamílias de leguminosas, objetivou-se avaliar o grau de influência da remoção de cotilédones no desenvolvimento de ramificações nas axilas cotiledonares e na sobrevivência das plântulas nessas espécies.

\section{Material e métodos}

Para detectar a influência da permanência dos cotilédones sobre a rebrota nas axilas cotiledonares de plântulas de seis espécies de leguminosas (Phaseolus vulgaris L., Vigna unguiculata (L.) Walp., Leucaena leucocephala (Lam.) De Wit., Prosopis juliflora (Sw.) DC., Tamarindus indica L. e Delonix regia L.), foram instalados experimentos inteiramente casualizados sob condições de viveiro. As sementes utilizadas foram colhidas de plantas existentes no campus da Escola Superior de Agricultura de Mossoró (ESAM), Mossoró, RN, exceto as de P. vulgaris (cv. Carioca Comum) e V. unguiculata (cv. Santa Inácia), que foram adquiridas no comércio.

Para permitir maior uniformidade de germinação, as sementes de $P$. vulgaris e $V$. unguiculata foram mantidas em água por 24 horas. As sementes de L. leucocephala foram também mantidas em água por 24 horas, tendo sido plantadas aquelas que mostraram nítida embebição. As sementes de P. juliflora foram 
submetidas à quebra de dormência em ácido sulfúrico concentrado por cinco minutos, sendo depois lavadas em água corrente e mantidas em água durante seis horas. A quebra de dormência das sementes de $T$. indica foi feita com ácido sulfúrico concentrado por 30 minutos, lavadas em água corrente e mantidas em água por 12 horas. As sementes de $D$. regia foram colocadas em ácido sulfúrico concentrado por três e meia horas $\mathrm{e}$ posteriormente lavadas em água corrente.

As plântulas que compuseram cada parcela foram obtidas a partir de sementes de aparência vigorosa semeadas em uma mistura de esterco bovino e areia, na proporção de 1:1. Em todas as parcelas foram semeadas de 150 a 300 sementes, dependendo da espécie, com base em testes prévios de germinação, desbastando-se as parcelas quando o número de plântulas ultrapassava 100 unidades. A população inicial de cada repetição foi de 100 plântulas para $P$. vulgaris e $V$. unguiculata, 87 a 100 plântulas para $L$. leucocephala, 86 a 100 para $P$. juliflora, 11 a 49 para $T$. indica e 6 a 63 para $D$. regia. Esses números variaram devido à desuniformidade de germinação das sementes, apesar da realização de tratamentos de quebra de dormência.

As plântulas tiveram suas hastes primárias (epicótilos) podadas na porção mediana do entrenó acima do nó cotiledonar antes de serem submetidas aos tratamentos. Esta poda foi realizada no primeiro dia da emergência nos experimentos com $P$. vulgaris e V. unguiculata. Em L. leucocephala e $P$. juliflora, a poda só pôde ser realizada nos terceiro e quinto dias após a emergência, respectivamente, devido à lentidão do crescimento do epicótilo. Nas plântulas de $T$. indica e $D$. regia, a poda foi realizada no mesmo dia da remoção dos cotilédones, exceto no tratamento sem remoção de cotilédones, que foi feita aos três dias da emergência, para evitar a remoção forçada dos cotilédones.

As plântulas foram submetidas aos seguintes tratamentos, com três repetições: (a) Remoção de ambos os cotilédones, no primeiro dia da emergência; (b) Remoção de ambos os cotilédones, no segundo dia da emergência; (c) Remoção de ambos os cotilédones, no terceiro dia da emergência; (d) Remoção de um só cotilédone, no primeiro dia da emergência; (e) Não remoção de cotilédones.

Foram feitas, em todas as parcelas, observações diárias, anotando-se o número de plântulas ramificadas e a localização dessas ramificações, bem como a evolução das populações de plântulas. Considerou-se como plântula recuperada aquela que apresentasse pelo menos uma ramificação.

As análises de variância (experimentos em esquema fatorial) e contrastes de médias foram realizados conforme Gomes (1990), e as transformações de dados, segundo Sokal \& Rohlf (1997).

\section{Resultados}

Em $P$. vulgaris, a remoção de um ou ambos os cotilédones não influenciou significativamente a recuperação das plântulas, ou seja, em todos os tratamentos, a maioria das plântulas, aos 18 dias após a poda dos epicótilos, apresentou ramificações nas axilas cotiledonares, sendo que todas as plântulas sem ramificação axilar (cerca de 7\%) se encontravam ainda vivas (Tab. 1, 2, 3). No tratamento em que foi removido apenas um cotilédone, $76,3 \%$ das plântulas apresentaram ramificações em ambas as axilas, 16,0\% em uma única axila e $7,7 \%$ não apresentaram ramificação alguma (Tab. 4).

Em V. unguiculata, a remoção de ambos os cotilédones no primeiro dia da emergência afetou significativamente o percentual de plântulas recuperadas; aos 15 dias após a poda dos epicótilos, cerca de $95 \%$ das plântulas encontravam-se recuperadas, isto é, com ramificação em pelo menos uma axila cotiledonar, sendo que as restantes ainda permaneciam vivas; em todos os outros tratamentos, houve $100 \%$ de recuperação de plântulas (Tab. 1 , $2,3)$. Houve ramificações em ambas as axilas cotiledonares em $91,6 \%$ das plântulas das quais se removeu apenas um cotilédone (Tab. 4).

Em L. leucocephala, a remoção de ambos os cotilédones reduziu significativamente os percentuais de plântulas recuperadas (Tab. 1, 2). Das plântulas submetidas à remoção de um ou nenhum cotilédone, $97,8 \%$ e $92,0 \%$, respectivamente, desenvolveram ramificações, percentuais esses não significativamente diferentes entre $s i$, mas significativamente superiores aos percentuais 
Tabela 1. Percentuais médios ${ }^{1}$ de plântulas ramificadas nas axilas cotiledonares em seis espécies de leguminosas em resposta a tratamentos de remoção de cotilédones.

\begin{tabular}{lcccccc}
\hline \multicolumn{1}{l}{ Tratamentos } & \multicolumn{5}{c}{ Plântulas ramificadas (\%) } \\
\cline { 2 - 7 } & $\begin{array}{l}\text { Phaseolus } \\
\text { vulgaris }\end{array}$ & $\begin{array}{c}\text { Vigna } \\
\text { unguiculata }\end{array}$ & $\begin{array}{c}\text { Leucaena } \\
\text { leucocephala }\end{array}$ & $\begin{array}{c}\text { Prosopis } \\
\text { juliflora }\end{array}$ & $\begin{array}{c}\text { Tamarindus } \\
\text { indica }\end{array}$ & $\begin{array}{c}\text { Delonix } \\
\text { regia }\end{array}$ \\
\hline $\begin{array}{l}\text { Remoção dos dois cotilédones } \\
\text { no 1- dia da emergência }\end{array}$ & $88,7 \mathrm{aA}$ & $94,7 \mathrm{aA}$ & $06,0 \mathrm{aBC}$ & $6,6 \mathrm{aBC}$ & $2,7 \mathrm{aB}$ & $14,2 \mathrm{aC}$ \\
$\begin{array}{l}\text { Remoção dos dois cotilédones } \\
\text { no 2\% dia da emergência }\end{array}$ & $92,3 \mathrm{aA}$ & $100,0 \mathrm{bB}$ & $16,2 \mathrm{aC}$ & $13,7 \mathrm{aC}$ & $10,6 \mathrm{aC}$ & $14,4 \mathrm{aC}$ \\
$\begin{array}{l}\text { Remoção dos dois cotilédones } \\
\text { no 3- dia da emergência }\end{array}$ & $90,3 \mathrm{aA}$ & $100,0 \mathrm{bB}$ & $15,6 \mathrm{aC}$ & $19,2 \mathrm{aC}$ & $41,4 \mathrm{bD}$ & $36,5 \mathrm{bD}$ \\
$\begin{array}{l}\text { Remoção de um só cotilédone } \\
\text { no 1- dia da emergência }\end{array}$ & $92,3 \mathrm{aAC}$ & $100,0 \mathrm{bBD}$ & $97,8 \mathrm{bABD}$ & $98,7 \mathrm{bBD}$ & $81,2 \mathrm{cC}$ & $100,0 \mathrm{cD}$ \\
\begin{tabular}{l} 
Remoção de nenhum cotilédone \\
\hline
\end{tabular} & $92,7 \mathrm{aAE}$ & $100,0 \mathrm{bBD}$ & $92,0 \mathrm{bABE}$ & $100,0 \mathrm{bCD}$ & $84,4 \mathrm{cE}$ & $100,0 \mathrm{cCD}$ \\
\hline
\end{tabular}

'Análise de variância e contrastes de médias realizados sobre os dados transformados em arcoseno $\sqrt{\mathrm{x} / 100}$ médias seguidas pela mesma letra minúscula, na coluna, e maiúscula, na linha, não diferem significativamente ao nível de $5 \%$, pelo teste de Tukey; $\mathrm{CV}=$ $7,6 \%$.

Tabela 2. Evolução dos percentuais médios' do surgimento de ramificações nas axilas cotiledonares de plântulas de seis espécies de leguminosas em cinco tratamentos de remoção de cotilédones.

Tratamentos Plântulas com ramificações axilares (\%)

\begin{tabular}{|c|c|c|c|c|c|}
\hline $\begin{array}{c}\text { Phaseolus } \\
\text { vulgaris }\end{array}$ & $\begin{array}{c}\text { Vigna } \\
\text { unguiculata }\end{array}$ & $\begin{array}{c}\text { Leucaena } \\
\text { leucocephala }\end{array}$ & $\begin{array}{l}\text { Prosopis } \\
\text { juliflora }\end{array}$ & $\begin{array}{c}\text { Tamarindus } \\
\text { indica }\end{array}$ & $\begin{array}{c}\text { Delonix } \\
\text { regia }\end{array}$ \\
\hline $\begin{array}{c}\text { dias após } \\
\text { emergência }\end{array}$ & $\begin{array}{l}\text { dias após } \\
\text { emergência }\end{array}$ & $\begin{array}{c}\text { dias após } \\
\text { emergência }\end{array}$ & $\begin{array}{c}\text { dias após } \\
\text { emergência }\end{array}$ & $\begin{array}{c}\text { dias após } \\
\text { emergência }\end{array}$ & $\begin{array}{c}\text { dias após } \\
\text { emergência }\end{array}$ \\
\hline $\begin{array}{lll}4 & 8 & 18 \\
\end{array}$ & $8 \quad 15$ & 17 & $\begin{array}{lll}9 & 15 & 21\end{array}$ & 111621 & 16 \\
\hline
\end{tabular}

Remoção dos dois cotilédones no $1^{\text {- }}$ dia da emergência

\begin{tabular}{lllllllllllllllll}
62 & 86 & 88 & 87 & 94 & 95 & 5 & 9 & 0 & 0 & 7 & 0 & 2 & 3 & 15 & 14 \\
77 & 88 & 92 & 100 & 100 & 100 & 3 & 25 & 0 & 0 & 14 & 0 & 16 & 11 & 13 & 14 \\
76 & 87 & 90 & 98 & 100 & 100 & 3 & 33 & 0 & 0 & 9 & 0 & 42 & 41 & 9 & 37 \\
68 & 88 & 92 & 99 & 100 & 100 & 95 & 98 & 21 & 99 & 99 & 69 & 79 & 81 & 44 & 100 \\
7 & 66 & 93 & 100 & 100 & 100 & 94 & 92 & 98 & 100 & 100 & 40 & 59 & 84 & 90 & 100 \\
\hline
\end{tabular}

Remoção dos dois cotilédones no $2^{\circ}$ - dia da emergência Remoção dos dois cotilédones no 3ำ dia da emergência Remoção de um só cotilédone no $1^{\circ}$ - dia da emergência Remoção de nenhum cotilédone

'Valores arredondados para unidades.

médios observados nos outros três tratamentos. $\mathrm{Na}$ última observação (Tab. 3), aos 17 dias da emergência, nos tratamentos em que foram removidos ambos os cotilédones até o segundo dia da emergência, foram obtidos percentuais médios de mortalidade equivalentes a $33,3 \%$ e $34,0 \%$ do estande inicial médio, percentuais esses não significativamente diferentes entre si. Todavia, o percentual de mortalidade de plântulas $(54,7 \%)$, no tratamento em que ambos os cotilédones foram removidos no terceiro dia da emergência, apresentou-se significativamente superior aos dos outros tratamentos. Esse percentual pode ter sido influenciado por ataques de insetos ou microrganismos, cujos danos puderam ser constatados em algumas parcelas. No tratamento em que foi removido um ou nenhum cotilédone, os percentuais de mortalidade de plântulas foram significativamente inferiores $(2,2 \%$ e $8,0 \%$, respectivamente). Contudo, a morte das plântulas em todos os tratamentos somente ocorreu após o surgimento de pelo menos uma ramificação. As plântulas com uma única ramificação axilar, no tratamento em que apenas um cotilédone foi 
Tabela 3. Percentuais médios de plântulas mortas no final do período de observação em resposta a tratamentos de remoção de cotilédones.

\begin{tabular}{|c|c|c|c|c|c|c|}
\hline \multirow[b]{2}{*}{ Tratamentos } & \multicolumn{6}{|c|}{ Plântulas mortas (\%) } \\
\hline & $\begin{array}{c}\text { Phaseolus } \\
\text { vulgaris }\end{array}$ & $\begin{array}{c}\text { Vigna } \\
\text { unguiculata }\end{array}$ & $\begin{array}{c}\text { Leucaena } \\
\text { leucocephala }\end{array}$ & $\begin{array}{l}\text { Prosopis } \\
\text { juliflora }\end{array}$ & $\begin{array}{l}\text { Tamarindus } \\
\text { indica }\end{array}$ & $\begin{array}{l}\text { Delonix } \\
\text { regia }\end{array}$ \\
\hline $\begin{array}{l}\text { Remoção dos dois cotilédones } \\
\text { no } 1 \text { - dia da emergência }\end{array}$ & 0,0 & 0,0 & $33,3 \mathrm{aA}$ & $93,4 \mathrm{aB}$ & $97,3 \mathrm{aB}$ & $5,8 \mathrm{aC}$ \\
\hline $\begin{array}{l}\text { Remoção dos dois cotilédones } \\
\text { no } 2^{\circ} \text { - dia da emergência }\end{array}$ & 0,0 & 0,0 & $34,0 \mathrm{aA}$ & $86,3 \mathrm{aB}$ & $88,4 \mathrm{bB}$ & $85,6 \mathrm{aB}$ \\
\hline $\begin{array}{l}\text { Remoção dos dois cotilédones } \\
\text { no } 3 \text { - dia da emergência }\end{array}$ & 0,0 & 0,0 & $54,7 \mathrm{bA}$ & $90,8 \mathrm{aB}$ & $51,6 \mathrm{cA}$ & $63,5 \mathrm{bA}$ \\
\hline $\begin{array}{l}\text { Remoção de um só cotilédone } \\
\text { nol- dia da emergência }\end{array}$ & 0,0 & 0,0 & $2,2 \mathrm{cA}$ & $1,4 \mathrm{bA}$ & $18,8 \mathrm{~dB}$ & $0,0 \mathrm{cA}$ \\
\hline Remoção de nenhum cotilédone & 0,0 & 0,0 & $8,0 \mathrm{cA}$ & $0,0 \mathrm{bB}$ & $15,6 \mathrm{dA}$ & $0,0 \mathrm{cB}$ \\
\hline
\end{tabular}

'Análises de variância e contrastes de médias realizados sobre os dados transformados em arcoseno $\sqrt{x / 100}$ médias seguidas pela mesma letra minúscula, na coluna, ou maiúscula, na linha, não diferem significativamente ao nível de $5 \%$, pelo teste de Tukey; CV = $12,8 \%$.

Tabela 4. Percentuais médios de plântulas ramificadas conforme a localização das ramificações, no tratamento em que foi removido apenas um cotilédone.

\begin{tabular}{lcccccc}
\hline Localização da ramificação & $\begin{array}{c}\text { Phaseolus } \\
\text { vulgaris }\end{array}$ & $\begin{array}{c}\text { Vigna } \\
\text { unguiculata }\end{array}$ & $\begin{array}{c}\text { Leucaena } \\
\text { leucocephala }\end{array}$ & $\begin{array}{c}\text { Prosopis } \\
\text { juliflora }\end{array}$ & $\begin{array}{c}\text { Tamarindus } \\
\text { indica }\end{array}$ & $\begin{array}{c}\text { Delonix } \\
\text { regia }\end{array}$ \\
\hline Em nenhuma axila & 7,7 & 0,0 & 0,0 & 0,0 & 3,1 & 1,4 \\
Em uma única axila' & 16,0 & 8,4 & 6,1 & 19,0 & 5,7 & 10,3 \\
Em ambas as axilas & 76,3 & 91,6 & 93,9 & 81,0 & 91,2 & 88,3 \\
\hline
\end{tabular}

'Neste caso a única ramificação existente encontrava-se raramente na axila correspondente ao cotilédone removido.

removido no primeiro dia da emergência, representaram $6,1 \%$ do total, tendo o restante apresentado uma ramificação em cada axila (Tab. 4).

Em $P$. julifora, a remoção de ambos os cotilédones reduziu significativamente os percentuais de plântulas recuperadas em relação aos tratamentos em que foi removido um ou nenhum cotilédone (Tab. 1). Onde houve remoção de ambos os cotilédones, o surgimento das ramificações ocorreu somente aos 21 dias da emergência (Tab. 2), tendo sido bastante elevados os percentuais de plântulas mortas $(86,3$ a 93,4\%) nesses tratamentos (Tab. 3). Das plântulas ramificadas obtidas no tratamento em que foi removido um único cotilédone, $81,0 \%$ apresentaram ramificações em ambas as axilas e o restante em apenas uma (Tab. 4).

Em $T$. indica, a recuperação de plântulas foi mais afetada pela remoção de ambos os cotilédones nos primeiro e segundo dias da emergência do que pela remoção de ambos os cotilédones no terceiro dia. Os tratamentos de remoção de um ou nenhum cotilédone mostraramse indiferentes, tendo seus percentuais de plântulas ramificadas superado os obtidos nos outros tratamentos (Tab. 1). O início do surgimento das ramificações nos tratamentos em que se removeu um cotilédone ou nenhum ocorreu aos 11 dias da emergência, ao passo que nos outros tratamentos esse surgimento se deu somente aos 16 dias (Tab. 2). A mortalidade de plântulas foi significativamente decrescente quanto mais tardiamente foram removidos ambos os cotilédones, tendo essa mortalidade sido superior às verificadas nos outros dois tratamentos (Tab. 3). Das plântulas ramificadas obtidas no tratamento em que se removeu apenas um cotilédone, 91,2\% apresentaram-se com ramificações em ambas as axilas (Tab. 4).

Em D. regia, os percentuais de plântulas ramificadas obtidos em todos os tratamentos apresentaram comportamento similar aos obtidos em $T$. indica (Tab. 1), porém, o início do surgimento 
das ramificações ocorreu aos sete dias da emergência (Tab. 2). No que diz respeito à mortalidade de plântulas, a remoção de ambos os cotilédones até o segundo dia da emergência causou mais efeito do que a remoção no terceirto dia, porém não houve plantas mortas nos outros tratamentos (Tab. 3). No tratamento em que se removeu apenas um cotilédone, $98,6 \%$ das plântulas apresentaram ramificações em pelo menos uma axila (Tab. 4).

$P$. vulgaris e $V$. unguiculata não diferiram entre si quanto ao efeito da remoção de ambos os cotilédones no primeiro dia da emergência, mas os percentuais de plântulas ramificadas foram superiores aos apresentados pelas outras quatro espécies, das quais, entre si, diferiram apenas $T$. indica e D. regia (Tab. 1).

Não houve diferença significativa entre $L$. leucocephala, $P$. juliflora, $T$. indica e D. regia no que se refere aos percentuais de plântulas com ramificações axilares no tratamento em que foram removidos ambos os cotilédones no segundo dia da emergência, todavia apresentaram percentuais muito inferiores aos obtidos em $P$. vulgaris e V. unguiculata, tendo estas diferido entre si (Tab. 1).

Quando foram removidos ambos os cotilédones no terceiro dia da emergência, o percentual de plântulas ramificadas foi significativamente maior em $V$. unguiculata que em $P$. vulgaris, tendo esta, por sua vez, apresentado percentual maior que $T$. indica e D. regia, que se mostraram superiores a L. leucocephala e P. juliflora (Tab. 1).

Quando foi removido um só cotilédone, não houve muita diferença no percentual de plântulas ramificadas entre as espécies, contudo os menores valores foram obtidos em $P$. vulgaris e T. indica (Tab. 1). Nessas plântulas, observou-se raramente ramificação axilar correspondente ao cotilédone removido, enquanto não havia ramificação na axila do cotilédone não removido.

Em se tratando da mortalidade de plântulas, os tratamentos não afetaram $P$. vulgaris e $V$. unguiculata. Porém, nas outras espécies, a remoção de ambos os cotilédones causou efeito considerável, sendo menos expressivo em $L$. leucocephala (Tab. 3).
Observou-se que as plântulas, das quais foram removidos ambos os cotilédones, eram de menor porte que aquelas que tiveram apenas um ou nenhum cotilédone removido (dados não apresentados).

\section{Discussão}

Os cotilédones exercem papel fundamental pelo menos no desenvolvimento inicial da planta, fornecendo às outras partes da planta substâncias essenciais neles armazenadas durante o desenvolvimento do embrião ou produzidas durante a germinação e/ou desenvolvimento pós-emergência. No presente trabalho foi verificado que a remoção de ambos os cotilédones provoca, geralmente, diminuição da capacidade de rebrota nas axilas cotiledonares.

Na maioria das espécies estudadas, a remoção de ambos os cotilédones nos três primeiros dias da emergência, em plântulas cujos ápices epicotilares sofreram excisão, diminuiu drasticamente a capacidade de a plântula produzir brotações nas axilas cotiledonares e sua possibilidade de sobreviver se os cotilédones não apresentam altos teores de reservas como, por exemplo, em $V$. unguiculata e $P$. vulgaris. Isto está de acordo com Brakke \& Gardner (1987), no sentido de que a utilização da energia armazenada na semente, nos estádios iniciais de desenvolvimento da planta, é mais rápida nas espécies cujos cotilédones são maiores.

O surgimento de ramificações nas axilas cotiledonares de $P$. juliflora e $T$. indica, nos tratamentos em que foram removidos ambos os cotilédones, ocorreu mais tardiamente que no tratamento em que se removeu um ou nenhum cotilédone. Este fato, que é conseqüência da redução na velocidade de crescimento, embora não tenha se apresentado nítido em $L$ leucocephala e $D$. regia, é uma resposta similar àquelas obtidas com outras espécies cujos cotilédones são fotossintetizantes ativos (Arasaki \& Felippe 1990; Sassaki \& Felippe 1992; Paulilo \& Felippe 1994; Holland et al. 1995; Bonfil 1998).

Como os resultados aqui relatados foram obtidos em plântulas cujos ápices epicotilares foram removidos, depreende-se que o papel dos cotilédones inclui também a produção e o transporte de reguladores de crescimento, como já sugerido por Nandi \& Palni (1989), Gambley \& Dood (1991) e Yang et al. (1995). Isto pode 
explicar os altos percentuais de mortalidade de plântulas obtidos nos tratamentos em que ambos os cotilédones foram removidos, e os baixos percentuais de mortalidade de plântulas das quais se removeu apenas um cotilédone.

Nas plântulas em que foi removido apenas um cotilédone, observou-se raramente ramificação axilar correspondente ao cotilédone removido enquanto não havia ramificação na axila do cotilédone não removido, o que está de acordo com Desbiez et al. (1991), que demonstraram, utilizando plântulas de Bidens pilosa, haver um mecanismo envolvendo transporte, armazenamento e recuperação da mensagem de quebra de assimetria, que controla a taxa de crescimento das gemas cotiledonares. Também é possível que a remoção do cotilédone provoque diminuição da pressão de turgor nas células dos tecidos da axila correspondente, à maneira do que ocorreu (paralisação do alongamento celular) na região subapical dos hipocótilos de plântulas de Helianthus annuus estudadas por Kutschera \& Kohler (1994), retardando a atividade citocinética na região meristemática da axila do cotilédone removido. É digno de nota também que traumatismos causados nos cotilédones de B. pilosa resultaram na inibição da atividade da ATPase no plasmalema das células do hipocótilo (Bonnin et al. 1996).

Como os resultados aqui relatados forneceram alguns indícios de que existem semelhanças no papel dos cotilédones entre certos grupos de espécies de leguminosas, sugere-se a realização de estudos concernentes à anatomia e à química dos cotilédones, incluindo maior número de espécies, para que se possa determinar se os comportamentos metabólicos desses ógãos são correlacionados morfológica e/ou taxonomicamente.

\section{Agradecimentos}

Ao CNPq, pela concessão de bolsa de iniciação científica ao segundo Autor.

\section{Referências bibliográficas}

Arasaki, F. R. \& Felippe, G. M. 1990. Crescimento inicial de Kielmeyera coriacea. Ciência e Cultura 42: 716-720.

Bonfil, C. 1998. The effects of seed size, cotyledon reserves, and herbivory on seedling survival and growth in Quercus rugosa and $Q$. laurina (Fagaceae). American Journal of Botany 85: 79-87.
Bonnin, P.; Pichon, O.; Petel, G. \& Desbiez, M. O. 1996. Plasmalemma ATPase activity modifications induced by traumatisms in Bidens pilosa. Journal of Experimental Botany 47: 831-836.

Brakke, M. P. \& Gardner, F. P. 1987. Juvenile growth in pigeonpea, soybean, and cowpea in relation to seed and seedling characteristics. Crop Science 27: 311-316.

Chin, H. F.; Neales, T. F. \& Wilson, J. H. 1977. The effects of cotyledon excision on growth and leaf senescence in soyabean plants. Annals of Botany 41: 771-777.

Desbiez, M. O.; Tort, M. \& Thellier, M. 1991. Control of a symmetry-breaking process in the course of the morphogenesis of plantlets of Bidens pilosa L. Planta 184: $397-402$.

Gambley, R.L. \& Dood, W.A. 1991. The influence of cotyledons in axillary and adventitious shoot production from cotyledonary nodes of Cucumis sativus L. (cucumber). Journal of Experimental Botany 42: 11311135.

Gomes, F. P. 1990. Curso de Estatística Experimental. 13 ed. Nobel, São Paulo.

Holland, D.; Abied, M. A.; Nachman, S. \& Saad, S. 1995. Cotyledon detachment inhibits development but does not affect precocious flowering of 'Duncan' grapefruit. Plant cell, tissue and organ culture 41: 78-82.

Kutschera, U. \& Kohler, K. 1994. Cell elongation, turgor and osmotic pressure in developing sunflower hypocotyls. Journal of Experimental Botany 45: 591-595.

Meletiou-Christou, M. S.; Dianantoglou, S. \& Mitrakus, K. 1990. Analysis of lipids of Citrullus lanatus (cv. Sugar baby) during seed germination and seedling growth. Journal of Experimental Botany 41: 14551460 .

Nandi, S. K. \& Palni, L. M. S. 1989. Transport and metabolism of dihydrozeatin riboside in germinating lupin seeds. Journal of Experimental Botany 40: 615-621.

Paulilo, M. T. S. \& Felippe, G. M. 1994. Contribuição dos cotilédones e partição de matéria durante o crescimento inicial de Qualea grandiflora Mart. (Vochysiaceae). Revista Brasileira de Botânica 17: 87-91.

Sassaki, R. M. \& Felippe, G. M. 1992. Remoção dos cotilédones e desenvolvimento inicial de Dalbergia miscolobium. Revista Brasileira de Botânica 15: 5-16.

Silsbury, H. \& Silsbury, J. H. 1992. Nodulation and nitrogen fixation of faba bean (Vicia faba L.) as affected by removal of the cotyledons and nitrate supply. Annals of Botany 69: 271-281.

Sokal, R. R. \& Rohlf, F. J. 1997. Biometry. 3 ed. W. H. Freeman and Co., New York

Sunarpi \& Anderson, J. W. 1995. Mobilization of sulphur in soybean cotyledons during germination. Crop Physiology Abstracts 21(5): 538.

Yang, Y. Y.; Yamaguchi, 1.; Takeno-Wada, K.; Suzuki, Y. \& Murofushi, N. 1995. Metabolism and translocation of gibberelins in seedlings of Pharbitis nil. I. Effect of photoperiod on stem elongation and endogenous gibberelins in cotyledons and their phloem exudates. Plant and Cell Physiology 36: 221-227. 